\title{
New continuous wave infrared Ar-Xe laser at intermediate gas pressures pumped by a transverse radio frequency discharge
}

\author{
Y. B. Udalov, P. J. M. Peters, M. B. Heeman-llieva, F. H. J. Ernst, V. N. Ochkin, ${ }^{\text {a) }}$ \\ and W. J. Witteman \\ Department of Applied Physics, University of Twente, P.O. Box 217, 7500 AE Enschede, The Netherlands
}

(Received 14 January 1993; accepted for publication 26 May 1993)

\begin{abstract}
An atomic Xe laser with a transverse rf excitation has been operated in a cw mode in the intermediate pressure regime. The laser output spectrum consisted of $5 \mathrm{Xe}$ lines with wavelengths of $2.03,2.63,2.65,3.37$, and $3.51 \mu \mathrm{m}$. The unoptimized total output power of 330 $\mathrm{mW}$ was obtained for a gas mixture $\mathrm{Ar}: \mathrm{He}: \mathrm{Xe}=59: 40: 1$ at a pressure of 85 Torr and a rf input power of $150 \mathrm{~W}$ and excitation frequency of $121 \mathrm{MHz}$.
\end{abstract}

The pulsed atomic Xe laser recently showed high efficiency operation combined with high output energy. ${ }^{1-3}$ The laser generally oscillates on several lines ranging from 1.73 to $3.37 \mu \mathrm{m}$ covering an important band in the near-infrared part of the spectrum.

To pump the atomic Xe laser several well-known excitation techniques have been used, such as optical pumping with $\mathrm{CO}_{2}$ lasers, ${ }^{4} e$-beam ${ }^{5,6}$ and $e$-beam sustained ${ }^{7}$ discharges, transverse electrical atmospheric discharges, ${ }^{8,9}$ and even excitation with fission fragments. ${ }^{10,11}$ All these excitation techniques have been applied in a pulsed mode although in some devices pulse lengths of several milliseconds have been obtained. ${ }^{5,10,11}$ Also rf and microwave excitation in a waveguide structure have been used but only in a pulsed or burst mode. In 1980, Christensen et al. ${ }^{12}$ reported an output power of $30 \mathrm{~mW}$ from an active volume of $0.9 \mathrm{~cm}^{3}$ in a $25 \mu$ s pulse with a rf excitation frequency of $30 \mathrm{MHz}$. In 1988, the same group of NRL reported output pulses as long as $8 \mathrm{~ms}$ from a waveguide laser excited with microwave radiation with a microwave frequency of 915 $\mathrm{MHz} .{ }^{13} \mathrm{rf}$ excitation of rare gas mixtures such as He-Ar and $\mathrm{Ar}-\mathrm{Xe}$ were also investigated by a research group at Hughes Aircraft Company. They achieved $4.5 \mu \mathrm{J}$ per pulse or $90 \mathrm{~mW}$ average power at $20 \mathrm{kHz}$ pulse repetition rate with an efficiency of $0.1 \% .^{14}$ It was pointed out here that the rare-gas-based neutral gas laser systems prefer short excitation pulses with pulse lengths of $0.5-1 \mu \mathrm{s}$. Longer pulses did not increase the output power. $\mathrm{cw}$ lasing has been reported from both dc and longitudinal rf excited devices working at very low pressures. ${ }^{15,16}$ The maximum output power obtained in those experiments was usually a few milliwatts. ${ }^{15-17}$

In this letter we report on a real $\mathrm{cw}$ atomic Xe laser pumped by a transverse capacitively coupled $\mathrm{rf}$ discharge in the 100 Torr pressure region. In our experiments we used an Ar-Xe-He laser gas mixture and a rf excitation frequency of $121 \mathrm{MHz}$.

The experimental setup consists of a vacuum-tight laser head made of aluminum which simultaneously serves as the container for the gas mixture as well as the housing

\footnotetext{
a) Also at Low Temperature Plasma Optics Department, P. N. Lebedev Physics Institute, Russian Academy of Science, Leninsky Prosp., 53, 117924, Moscow, Russia.
}

for the laser electrodes. A discharge channel is formed by two metal electrodes and two dielectric sidewalls. As the Fresnel number for the longest wavelength observed in the experiments was about 1 it can be concluded that the dielectric properties of these sidewalls were not important with respect to the radiation propagation losses. The stainless steel electrodes and sidewalls formed a discharge channel with a cross section of $2.25 \times 2.25 \mathrm{~mm}^{2}$. The active lcngth of the channel was $37 \mathrm{~cm}$. $\Lambda$ water cooling system was connected to the ground electrode. The laser resonator of about $40-\mathrm{cm}$ length was formed by two reflectors, one totally reflecting mirror (a gold-coated quartz substrate, radius of curvature of $1 \mathrm{~m}$ ) and a silicon etalon.

Shunting coils have been connected in parallel to the laser electrodes to produce a homogeneous axial voltage distribution. An $L$-type matching circuit between the laser head and the rf power amplifier (Kalmus Eng., model $124 \mathrm{C}$, maximum output power of $500 \mathrm{~W}$ ) enabled us to work within $0.5 \%-1 \%$ power reflection range. The excitation frequency was set at $121 \mathrm{MHz}$. A bidirectional coupler was installed between the amplifier and the laser head to measure the input and reflected power levels. The rf power was measured with a Hewlett-Packard (HP437B) power meter. The laser output power was monitored with a broadband power/energy meter (Melles-Griot model BPEM 001). The laser radiation spectrum was measured with a set of narrow band optical filters which blocked all but one of the possible laser lines. We used five filters for the following wavelengths $1.73,2.03,2.63$ and $2.65,3.37$, and $3.51 \mu \mathrm{m}$. A liquid-nitrogen-cooled Ge-Au detector was used to monitor the signal.

The authors preliminarily investigated the performance of the laser as a function of gas composition and $\mathrm{rf}$ input power. Several gas mixtures starting from a heliumfree $\mathrm{Ar}: \mathrm{Xe}=99: 1$ and finishing with an argon $\mathrm{He}: \mathrm{Xe}=99: 1$ mixture have been studied. With the laser working in the cw mode it was found that for binary mixtures the laser output was rather low, generally less then $10 \mathrm{~mW}$. The discharge behavior differed for these binary mixtures dramatically, however. With the helium-free mixture it appeared to be almost impossible to get a stable discharge, while in argon-free mixtures the discharge remained fairly stable for pressures up to 350 Torr. Better results with respect to the laser output power have been obtained with 


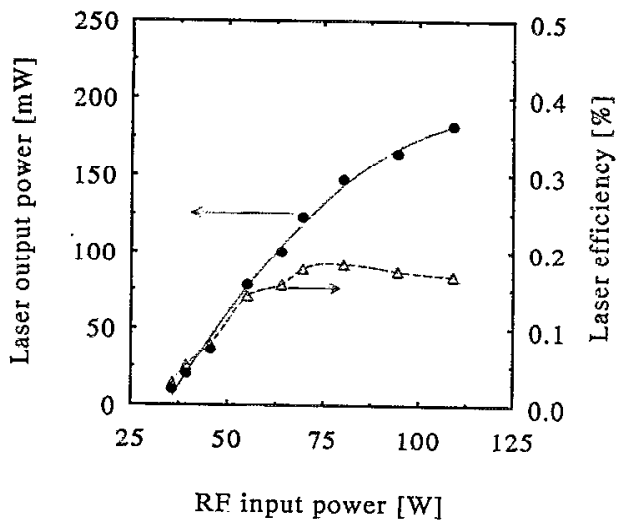

FIG. 1. Laser output power and efficiency as a function of If input power. The laser gas mixture is $\mathrm{Ar}: \mathrm{He}: \mathrm{Xe}=39: 60: 1$ at a pressure of 90 Torr.

ternary mixtures. A typical example of the laser output power as a function of the input power is shown in Fig. 1. The laser head was filled with a gas mixture Ar:He:Xe $=39: 60: 1$ at a total gas pressure of 90 Torr. The laser power increases with the pumping power. The laser efficiency is plotted in the same figure and is more or less constant at $0.2 \%$ for the higher output power levels. We did not perform a complete optimization procedure with respect to the optimal gas composition or cavity configuration. Until now a maximum output power level of 330 $\mathrm{mW}$ for a gas mixture Ar:He:Xe = 59:40:1 was obtained.

Spectral measurements of the laser output have been performed with the experimental technique mentioned above. It was found that the laser spectrum contained at least four lines with wavelengths of $2.03,2.63$ and 2.65 , 3.37 , and $3.51 \mu \mathrm{m}$. To separate the 2.63 and $2.65 \mu \mathrm{m}$ laser line we used a monochromator with a $150 \mathrm{l} / \mathrm{mm}$ grating blazed at $2 \mu \mathrm{m}$. A typical spectrum of the laser output is presented in Fig. 2. The line intensity distribution may be influenced by the outcoupling etalon with a free spectral range of about $20 \mathrm{GHz}$. All observed lines are attributed to the $5 d-6 p$ transition of the $\mathrm{Xe}$ atom. It can be seen that under our experimental conditions the maximum output power was obtained from the $5 d[3 / 2]_{1} \rightarrow 6 p[3 / 2]_{1}$ transition with a wavelength of $2.03 \mu \mathrm{m}$. The laser spectrum observed in our experiments was somewhat different from the one typical for the high-pressure pulsed atomic Xe laser. The $1.73 \mu \mathrm{m}$ radiation was not observed because of the high $\mathrm{He}$ concentration. On the other hand the $3.51 \mu \mathrm{m}$ transition found in our experiments normally only appeared at very low gas pressures. ${ }^{15,16}$

In summary we have demonstrated a $\mathrm{cw}$ atomic Xe

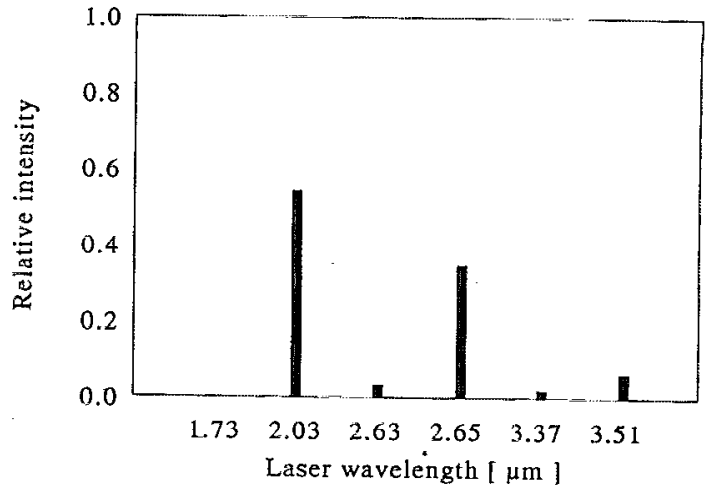

FIG. 2. Relative intensity of different laser lines for the laser gas mixture Ar:He:Xe $=39: 60: 1$ at a pressure of 90 Torr.

laser at intermediate pressures excited by a transverse rf discharge. An unoplimized output power of $330 \mathrm{~mW}$ was obtained at an efficiency of $0.2 \%$.

These investigations in the program of the Foundation for Fundamental Research on Matter (FOM) have been supported (in part) by the Netherlands Technology Foundation (STW).

'T. T. Perkins and J. H. Jacob, Proceedings CLEO, 1992 [OSA Tech. Dig. Ser, 12, 576 (1992)].

${ }^{2}$ H. Botma, P. J. M. Peters, and W. J. Witteman, Appl. Phys. B 52, 277 (1991).

${ }^{3}$ L. N. Litzenberger, D. W. Trainor, and H. W. McGeoch, IEEE J. Quantum Electron. QE-26, 1668 (1990).

${ }^{4}$ W. T. Silfvast, L. H. Szeto, and O. R. Wood II, J. Appl. Phys. 50, 7921 (1979).

${ }^{5}$ E. L. Patterson, G. E. Samlin, P. J. Brannon, and M. J. Hurst, IEEE J. Quantum Electron. QE-26, 1661 (1990).

${ }^{6}$ P. J. M. Peters, Y. F. Lan, M. Ohwa, and M. J. Kushner, IEEE J. Quantum Electron. QE-26, 1964 (1990).

${ }^{7}$ N. G. Basov, V. V. Baranov, A. Y. Chugunov, V. A. Danilychev, A. Y. Dudin, I. V. Kholin, N. N. Vstinorskii, and D. A. Zayarnyi, IEEE J. Quantum Electron. QE-21, 1756 (1985).

${ }^{8}$ K. Komatsu, F. Kannari, and M. Obara, J. Appl. Phys. 71, 5347 (1992).

${ }^{9}$ J. E. Tucker and B. L. Wexler, IEEE J. Quantum Electron. QE-26, 1647 (1990).

${ }^{10}$ W. J. Alford and G. H. Hays, J. Appl. Phys. 65, 3760 (1989).

${ }^{11}$ A. M. Voinov, A. I. Konak, S. P. Melnikov, and A. A. Syniansky, Sov. J. Quantum Electron. 21, 1179 (1989).

${ }^{12}$ C. P. Christensen, F. X. Powell, and N. Djeu, IEEE J. Quantum Electron. QE-16, 949 (1980).

${ }^{13}$ C. L. Gordon, B. Feldman, and C. P. Christensen, Opt. Lett. 13, 114 (1988).

${ }^{14}$ J. H. S. Wang, J. N. Paranto and C. M. Lovejoy, IEEE J. Quantum Electron. QE-10, 276 (1984).

${ }^{15}$ C. S. Willet, Introduction to Gas Lasers (Pergamon, Oxford, 1974), pp. 163-185.

${ }^{16}$ J. H. Shäfer, Phys. Rev. A 3, 752 (1971).

${ }^{17}$ C. C. Davis and T. A. King, Phys. Lett. 39, 186 (1972). 